\title{
Metagenomics to Unlock the Biotechnological Potential of Marine Environments
}

\author{
Michele de Cássia Pereira e Silva* \\ Federal University of São Carlos, Brazil \\ *Corresponding author: Michele de Cássia Pereira e Silva, Department of Environmental Sciences, Federal University of São Carlos, Rod. Joao Leme \\ dos Santos km 110, CEP 18052-780, Sorocaba, Brazi
}

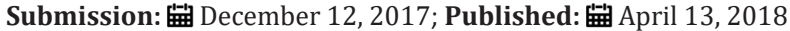

\section{Mini Review}

Microorganisms are involved and responsible for most of the biogeochemical cycles in both terrestrial and marine environments, such as carbon, nitrogen, phosphorus, sulfur and iron [1,2]. Their diversity and abundance is extremely high, in the air, in the soil and in the water. Microbes are ubiquitous, from extreme environments (called extremophiles) to more hospitable conditions, acidic or basic, wet or dry, saline, pollutedwith heavy metals or hydrocarbons, microorganisms are always there. Highlights from the Census of Marine Life (2010). Has revealed the unbelievable fact that the number of bacteria in the open oceanexceeds 1029, representing more than $90 \%$ ofthe total marine biomass, and more thanonemillion living bacteriain each millilitre of sea water [3]. Marine environment scomprise over $70 \%$ of theearth'ssurface, rangingfrom habitats in the freezing Arctic and Antarctic to the warm water soft hetropics [4]. Microorganisms live normally in association with countless number of other organisms, including bactéria, archaea, fungi, protists and viruses. [5] analyzed a marine water column by sequencing thousands of short rRNA gene sequences and they showed that even when these reads were grouped with identities that varied by as much as $10 \%$, the number of unique sequences in each sample remained in the thousands, exemplifying the astounding genetic and phenotypic diversity. Moreover, Venter et al., 2004 applied a whole genome sequence approach to samples obtained from the Sargasso Sea where they identified over 1.2 million unkonwn genes. This huge diversity has resulted in an acceleration of studies focusing on marine microbes not only with the purpose of understanding their importance on marine food webs and biogeochemical cycling, but also in exploiting their potential novel enzymes and metabolites/ compounds with potential biotechnological applications (Kennedy et al. 2008). A particular importante approach to start getting a glimpse of environmental taxonomic and metabolic diversity is metagenomics.

Metagenomics, defined as the direct genetic analysis of genomes contained with an environmental sample [6], allow the metabolic profiling of complex environmental samples $[7,8]$ and also the identification of novel molecules and enzymes
[9], by using either targeted gene sequencing or shot gunmetal genome sequencing. In the case a specific gene is targeted, DNA is isolated from environmental samples and purified prior to amplification with sequencing adaptors and specific primers. In shotgun sequencing approach, amplification with specific primes is not necessary and the extracted genomic DNA is fragmented and ligated with adaptors that will allow separation of multiple samples after sequencing. Both approaches generate a large number of reads that need to be further assembled and annotated to be further analysed. In metagenomic studies, the necessity of isolation or cultivation of microorganisms is avoided, as it is based on the direct isolation of genomic DNA from environmental samples [10]. This principle is especially important considering that most of the diversity found in environmental samples cannot be grown on an agar plate, less than $1 \%$ in terrestrial environments [11] and 0.001 to $0.1 \%$ in seawater [12]. In this scenario metagenomics constitutes a powerful tool to access this cultivable-inaccessible diversity. The diversity of conditions, which the microorganisms are exposed to (pressure, temperature, salinity and nutrient availability) acts as selective pressure on the microbial community possessing potentially unique molecules and enzymes that allow them to adapt and ultimately thrive in these conditions. For instance, novel enzymes have recently been identified from a non-specific nuclease isolated from a bacterio phage, which predates on the marine thermophile Geobacillus sp. 6K51 [13]. Moreover, genes encoding polyketide synthases (PKS), which are involved in the synthesis of pharmacologically relevant secondary metabolites from the marine environment have in the past been targeted in this way. For example, polyketide synthase (pks) genes, which are involved in the synthesis of pharmacologically relevant secondary metabolites, have previously been targeted from 20 different sponge metagenomes [14]. In addition, novel fumarase and alkane hydroxylase genes have also been cloned using sequence-based approaches from marine environments $[15,16]$. Other important enzymes have been isolated, such as a low-temperature active lipase from a metagenomic library of Baltic Sea marine sediment bacteria [17] and two novel esterases from surface seawater from the South China sea [18]. 
In summary, metagenomics and next generation sequencing technologies based on DNA/RNA have revolutionized microbiology and biotechnology, allowing the much faster discovery of new genes and important functions [19], from different organisms and from different environments. We must acknowledge the importance of traditional culture-based methods, which should be also considered in bio prospection studies. For sure we still far from know all the genetic and metabolic diversity of microbial communities out there however, such approaches offer significant promise and represent an incredible opportunity to identify potential novel genes, enzymes and other molecules, as well as to isolate and study the microorganisms responsible for important processes.

\section{References}

1. Falkowski PG, Fenchel T, Delong EF (2008) The microbial enginesthat drive earth's biogeochemical cycles. Science 320(5879): 1034-1039.

2. Zehr JP, Kudela RM (2011) Nitrogen cycle of the open ocean: from genes to ecosystems. Ann Rev Mar Sci 3: 197-225.

3. Calle F (2017) Marine microbiome as sourceof natural products. Microb Biotechnol 10(6): 1293-1296.

4. Kodzius R, Gojobori T (2015) Marine metagenomics as a source for bioprospecting. Marine genomics 24(Pt 1): 21-30.

5. Sogin ML, Morrison HG, Huber JA, Mark Welch D, Huse SM, et al. (2006) Microbial diversity in the deep sea and the underexplored "rare biosphere. Proc Natl Acad Sci USA 103(32): 12115-12120.

6. Thomas T, Gilbert J, Meyer F (2012) Metagenomics-a guide from sampling to data analysis. Microb Inform Exp 2(1): 3.

7. Tringe SG, von Mering C, Kobayashi A, Salamov AA, Chen K, et al. (2005) Comparative metagenomics of microbial communities. Science 308(5721): 554-557

8. Mai Z, Su H, Yang J, Huang S, Zhang S (2014) Cloning and characterization of a novel GH44 family endoglucanase from mangrove soil metagenomic library. Biotechnol Lett 36(8): 1701-1709.
9. Yang C, Xia Y, Qu H, Li A, Liu R (2016) Discovery of new cellulases from the metagenome by a metagenomics guided strategy. Biotechnology for Biofuels 9:138.

10. Biddle JF, Fitz-Gibbon S, Schuster SC, Brenchley JE, House CH (2008) Metagenomic signatures of the Peru Margin subsea floor biosphere show a genetically distinct environment. Proc Natl Acad Sci USA 105(30): 10583-10588.

11. Rappe MS, Giovannoni SJ (2003) The uncultured microbial majority. Annu Rev Microbiol 57: 369-394.

12. Amann RI, Ludwig W, Schleifer KH (1995) Phylogenetic identification and in situ detectionof individual microbial cells without cultivation. $\mathrm{Mi}$ crobiol Rev 59(1): 143-169.

13. Song Q Zhang X (2008) Characterization of a novel non-specific nuclease from thermophilic bacteriophage GBSV1. BMC Biotechnol 8: 43.

14. Fieseler L, Hentschel U, Grozdanov L, Schirmer A, Wen G, et al. (2007) Wide spread occurrence and genomic context of unusually small polyketide synthase genes in microbial consortiaassociatedwith marine sponges. Appl Environ Microbiol 73(7): 2144-2155.

15. Wasmund K, Burns KA, Kurtboke DP, Bourne DG (2009) Novel alkane hydroxylase gene (alkB) diversity in sediments associated with hydrocarbon seeps in the timor sea, Australia. FEMS Microbiol Ecol 68: 142-151.

16. Jiang C, Wu LL, Zhao GC, Shen PH, Jin K, et al. (2010) Identification and characterization of a novel fumarase gene bymetagenomeexpressioncloningfrom marine microorganisms. Microb Cell Fact 9: 91.

17. Hardeman F, Sjoling S (2007) Metagenomic approach for the isolation of a novel low-temperature-active lipase from uncultured bacteria of marine sediment. FEMS Microbiol Ecol 59: 524-534.

18. Chu X, He H, Guo C, Sun B (2008) Identification of two novel esterases from a marine metagenomic library derived from South China sea. Appl Microbiol Biotechnol 80(4): 615-625.

19. Dion P, Nautiyal CS (2008) (eds.), Microbiologyof Extreme Soils. In: Dion P, Nautiyal CS (Eds.), SoilBiology 13, Springer-Verlag Berlin Heidelberg, Germany.
Creative Commons Attribution 4.0 International License

For possible submissions Click Here

\section{Submit Article}

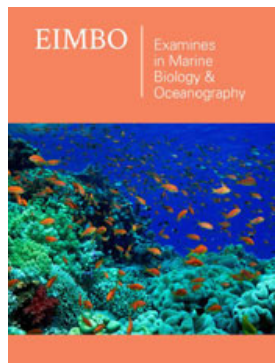

Examines in Marine Biology \& Oceanography

\section{Benefits of Publishing with us}

- High-level peer review and editorial services

- Freely accessible online immediately upon publication

- Authors retain the copyright to their work

- Licensing it under a Creative Commons license

- Visibility through different online platforms 